\title{
The Comparison between Two High-Temperature Heat-Pumps for the Production of Sanitary Water
}

\author{
Igor Ivanovski ${ }^{1}$ - Darko Goričanec ${ }^{2}$ - Julijan Jan Salamunić ${ }^{3}$ - Tina Žagar4,* \\ 1 IVD Maribor, Slovenia \\ 2 University of Maribor, Faculty of Chemistry and Chemical Engineering, Slovenia \\ 3 Inter oil d.o.o., Slovenia \\ ${ }^{4}$ Ministry of Economic Development and Technology, Slovenia
}

High-temperature heat-pumps are devices that exploit low-temperature heat sources for the production of hot water at high temperatures. This paper presents a comparison between two high temperature heat-pumps for the production of hot sanitary water of temperatures between $65^{\circ} \mathrm{C}$ and $85^{\circ} \mathrm{C}$. A high-temperature heat-pump that uses ammonia as a refrigerant and transcritical heat-pump that uses carbon dioxide as a refrigerant were compared in terms of coefficient of performance. Theoretical calculations were based on the REFPROP property method within Aspen Plus software. The simulations showed that the ammonia high-temperature heat-pump outperforms the transcritical heat-pump in terms of coefficient of performance within the evaporation temperature range between $-20{ }^{\circ} \mathrm{C}$ and $20{ }^{\circ} \mathrm{C}$.

Keywords: heat-pump, sanitary water, coefficient of performance

Highlights

- $\quad$ Paper presents modelling two high-temperature heat-pumps using REFPROP property method.

- $\quad$ Two refrigerants were compared, ammonia and $\mathrm{CO} 2$ in terms of COP.

- A double stage ammonia heat-pump has a higher COP than the transcritical heat-pump.

- Heat-pump technology is cheaper than the technology of transcritical heat-pumps.

\section{INTRODUCTION}

The EU has set a target to reduce greenhouse gas emissions by $80 \%$ to $95 \%$ until 2050 [1]. Heat-pumps could play an important role in achieving this goal as they are considered as one of the more important decarbonisation technologies for energy systems throughout the world. Traditional heat-pumps are suitable for low-temperature heating systems such as underfloor heating, low-temperature radiators or fan convection heaters. On the other hand, district heating system usually operates at higher temperature regimes. Therefore, high-temperature heat-pumps (HTHP) are suitable for the aforementioned purpose.

HTHP are devices that exploit low-temperature heat sources such as geothermal water, waste heat of refrigerators, industrial sources, etc. in order to produce hot water to be used for heating of buildings, for the production of sanitary hot water or in district heating systems.

HTHP usually employ ammonia as a refrigerant and can be used in many different applications. Kulcar et al [2] reported on exploiting heat from low-temperature geothermal sources. Goričanec et al [3] reported on exploiting low-temperature heat from the generators' cooling system within a hydro power plant. A study on the exploitation of lowtemperature energy sources from cogeneration gas engines was presented in [4]. A semi-empirical model was developed for high pressure twin compressors for the purpose of exploiting waste heat of refrigeration units [5]. A comparison between the installation of electric boilers or HTHP in distributed cogeneration was undertaken in the study on intermittency friendly energy system [6].

On the other hand, transcritical heat-pumps that use natural refrigerant carbon dioxide are getting an increasing attention [7]. Zha et al. [8] investigated a transcritical heat-pump with Voorhees economizer. Tao et al. performed a thermodynamic analysis of an ejector enhanced $\mathrm{CO}_{2}$ transcritical heat-pump [7]. An expander was used to replace the expansion valve to recover the expansion work in [9] and the influence of nitrogen was studied. Transcritical heat-pumps are suitable for the production of hot sanitary water, which requires a high-temperature lift, as the supercritical fluid is not condensed during the cycle, but it is cooled in the gas cooler.

Carbon dioxide and ammonia are the most promising amongst natural refrigerants, which could replace the refrigerants with global warming potential (GWP). Carbon dioxide has zero ozone depletion potential (ODP) and negligible GWP [9] On the other hand, ammonia has zero ODP and GWP.

There are a few disadvantages of using ammonia as a refrigerant, such as toxicity and flammability. On 
the other hand, ammonia has an extremely high latent heat, thus providing more heat flow per unit of mass flow than any other refrigerant used in the traditional compression refrigeration systems [10]. Also the acoustic velocity of ammonia is much higher than any other refrigerant, which means that higher gas velocities can be used in the design of pipes, valves and fittings without incurring substantial pressure losses [10].

The main disadvantages of $\mathrm{CO}_{2}$ as a refrigerant are high pressure of evaporation and gas cooling, and low theoretical coefficient of performance (COP). Despite of that, $\mathrm{CO}_{2}$ has excellent transport properties and high compressor efficiency, enabling to obtain high actual COP [11]. $\mathrm{CO}_{2}$ is also non-toxic, nonflammable, thermally stable, and compatible with other materials.

The goal of this study was to compare two natural refrigerants, ammonia and carbon dioxide for producing sanitary hot water within a hightemperature heat-pump and trans-critical heat-pump, respectively. The comparison was based on COP values, which were calculated during theoretical simulations using Aspen Plus software.

\section{METHODS}

\subsection{Single Stage HTHP}

Single stage HTHP consists of 4 main parts: a compressor, an evaporator, a condenser, and an expansion valve as shown in Fig. 1.

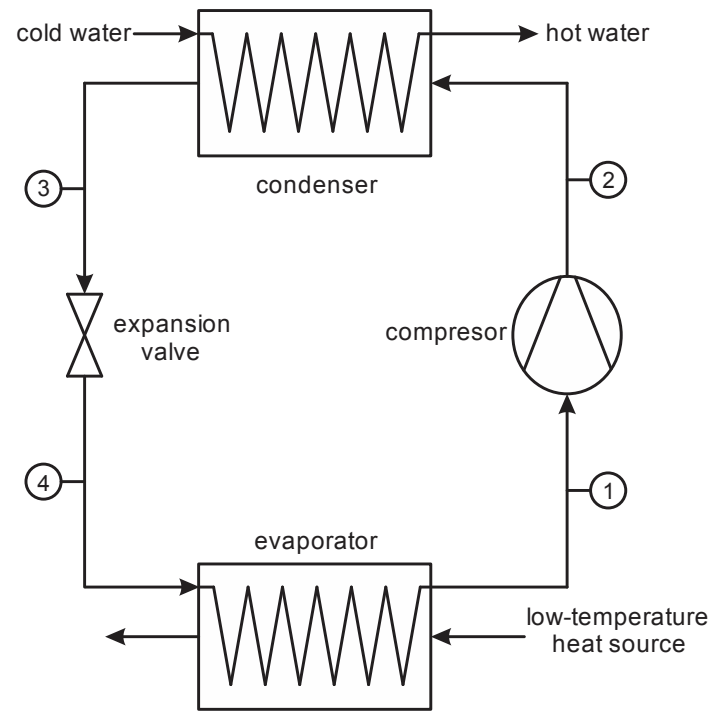

Fig. 1. Process flow diagram of single stage HTHP
The vapour refrigerant is first compressed from an evaporation pressure to a condensation pressure. The vapour is superheated in point 2; further on, it cools to a condensation temperature, then it condenses and further cools down to a discharge temperature in point 3 . The heat that is released during vapour cooling, condensation, and liquid sub cooling is transferred to sanitary water. The subcooled liquid refrigerant (point 3 ) is then reduced in pressure in an expansion valve. After the expansion the refrigerant evaporates in the evaporator. A low-temperature heat source is needed for this process.

\subsection{Double stage HTHP}

Double stage HTHP has an additional compressor and intercooler placed between both compressors as shown in Fig. 2. Cold water is conveyed to the intercooler and then to the condenser of the heat-pump. Double stage HTHP was used for evaporation temperatures below $10{ }^{\circ} \mathrm{C}$. The second compressor is needed because the pressure ratio of a compressor, which is defined as the quotient between the outlet pressure and inlet pressure of a compressor, cannot exceed 5. However, double stage HTHP could also be used for evaporation temperatures above $10^{\circ} \mathrm{C}$, which would lead to higher COP compared to a single stage HTHP because cold vapours require less work to compress.

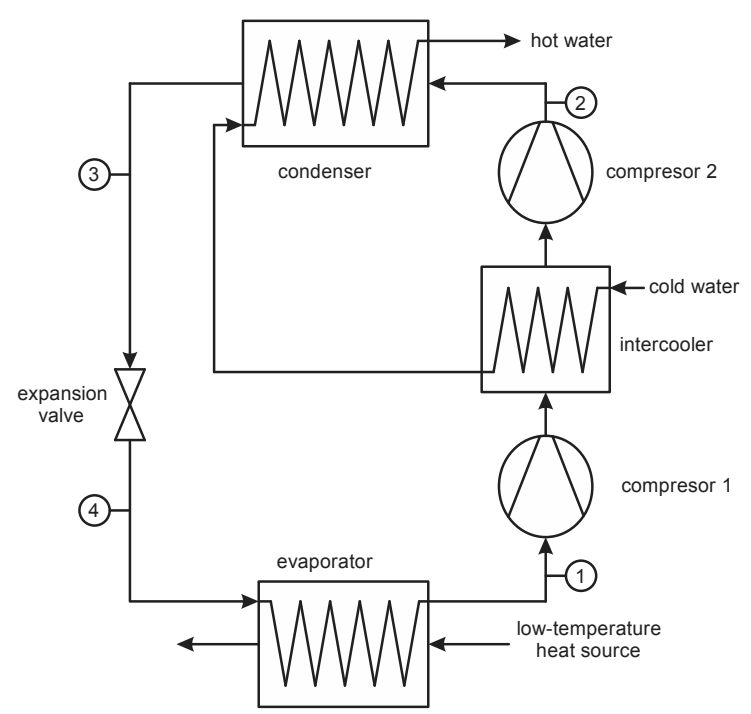

Fig. 2. Process flow diagram of double stage HTHP

\subsection{Transcritical Heat-Pump}

Transcritical heat-pump has nearly the same configuration as single stage HTHP, Fig. 3, except 
for an additional internal heat exchanger [8], and it has a gas cooler instead of a condenser. $\mathrm{CO}_{2}$ is compressed above the critical pressure of $71 \mathrm{bar}$, and cooled in a gas cooler, where the heat is released over a temperature range.

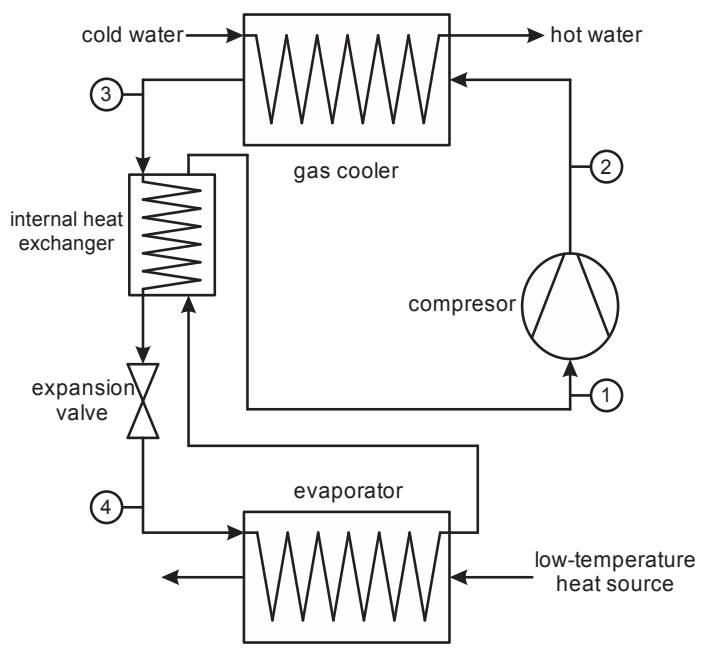

Fig. 3. Process flow diagram of transcritical heat-pump

This is in contrast to the conventional heatpumps, where the majority of heat is released at a constant temperature. After the gas cooler, the supercritical $\mathrm{CO}_{2}$ (point 3 ) is conveyed to an internal heat exchanger, where it is further cooled with the vaporised $\mathrm{CO}_{2}$ coming from the evaporator. After the reduction in pressure, liquid $\mathrm{CO}_{2}$ evaporates in the evaporator. The internal heat exchange increases COP of the whole system, because higher temperatures can be obtained at the compressor outlet.

\subsection{Simulations}

In the present study, the following simplifying assumptions were taken into account for the theoretical analysis of both heat-pumps:

- Refrigerant at the evaporator outlet was specified as saturated vapour.

- Zero pressure drop was assumed in all heat exchangers (condensers, gas coolers, evaporators, intercoolers, and internal heat exchanges), and connecting pipes.

- It was assumed that heat losses are negligible.

- An adiabatic, but non-isentropic compression process was assumed with isentropic efficiency of 0.7 [12] and 0.84 [3] and [4] for $\mathrm{CO}_{2}$ and ammonia compressors, respectively. Mechanical efficiency was set to 0.97 for both compressors.
- The refrigerant temperature at the outlet of the gas cooler was set at $35{ }^{\circ} \mathrm{C}$. It was assumed that ammonia would also be subcooled after condensation in the condenser to the same temperature.

- The temperature of the inlet sanitary water was assumed to be $15^{\circ} \mathrm{C}$.

- Evaporation temperatures were varied between $-20{ }^{\circ} \mathrm{C}$ and $20{ }^{\circ} \mathrm{C}$. In this temperature range, all types of heat sources could be used such as: geothermal water, heat of refrigeration equipment, and even outside air.

- The amount of produced hot water was fixed at $1.07 \mathrm{~kg} / \mathrm{s}$.

Outlet pressure of the high pressure compressor was varied during the simulations of heat-pumps in order to achieve the minimum approach temperatures of $10^{\circ} \mathrm{C}$ in the gas cooler/condenser in all simulation cases. The minimum approach temperature in the internal heat exchanger was also set to $10^{\circ} \mathrm{C}$.

REFPROP property method was used for all the simulations within Aspen Plus software program - a versatile modeling tool, which is relatively easy to use when modeling advanced chemical processes and power cycles. It provides a platform for describing different physical/chemical processes. ASPEN Plus can be used for model creation, sensitivity analyses, economics, and optimization. It has a broad physicalchemical property database with many built-in unit models such as compressors, pumps, heaters, heatexchangers, stream mixers, and stream splitters. In addition, the user can create model blocks based on the Fortran programing language. The REFPROP property method was developed by the National Institute of Standards and Technology (NIST). It is based on highly accurate pure fluid and mixture models. It implements 3 models for the determination of thermodynamic properties of pure fluids: equation of state explicit in Helmholz energy, the modified Benedict-Webb-Rubin equation of state, and an extended corresponding state model (ESC) [13] and [14].

COP values were calculated according to Eq. (1) for the single-stage HTHP and transcritical heatpump:

$$
\mathrm{COP}=\frac{\Phi}{W},
$$

where $\Phi$ is the rate of heat flow within the gas cooler or condenser [W], and $W$ is the work required to drive the compressor [W]. Eq. (2) was used for the calculation of the COP of the double-stage high temperature heat-pump: 


$$
\mathrm{COP}=\frac{\Phi_{C}+\Phi_{I}}{W_{1}+W_{2}}
$$

where $\Phi_{C}$ is the rate of heat flow within the condenser [W], $\Phi_{I}$ is the rate of heat flow within the intercooler [W], $W_{1}$ is the work required to drive the first compressor [W], and $W_{2}$ is the work required to drive the second compressor [W].

The calculations of COP values were done in an MS Excel spreadsheet. Afterwards, graphs were drawn in the same program.

\section{RESULTS AND DISCUSSION}

The condenser of the ammonia HTHP was simulated so that the ammonia was subcooled after condensing. Fig. 4 shows the temperature curves for the condenser of ammonia HTHP at evaporation temperature $\left(t_{e}\right)$ of $0{ }^{\circ} \mathrm{C}$ and sanitary water temperature $\left(t_{w}\right)$ of 75 ${ }^{\circ} \mathrm{C}$. This enables the full utilisation of the heat of the compressed refrigerant and even a lower compression ratio compared to condensation only. The temperature of the water at the condenser inlet was higher than 15 ${ }^{\circ} \mathrm{C}$ in the case of double stage heat-pump as the water was already partially heated within the intercooler. In order to keep the minimum approach temperatures of $10{ }^{\circ} \mathrm{C}$ in the condenser, the outlet pressure of the second compressor needed to be a bit higher than it would be in the case of a single stage heat-pump. Fig. 5 presents the temperature curves for the gas cooler of the transcritical $\mathrm{CO}_{2}$ heat-pump at evaporation temperature of $0{ }^{\circ} \mathrm{C}$ and sanitary water temperature of $75{ }^{\circ} \mathrm{C}$.

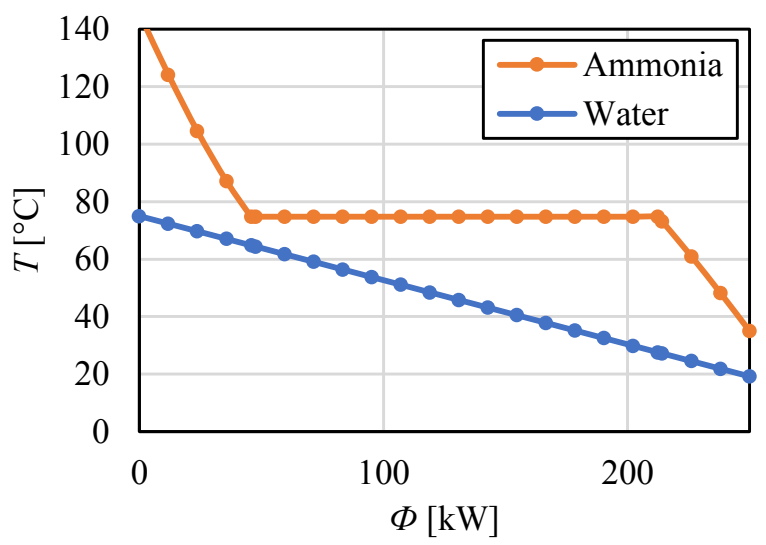

Fig. 4. Temperature curves for the condenser of High temperature heat-pump at $T_{e}=0{ }^{\circ} \mathrm{C} ; T_{w}=75^{\circ} \mathrm{C}$

The refrigerant was cooled to $35{ }^{\circ} \mathrm{C}$ in all the cases to allow for a fair comparison between both technologies. In the above mentioned cases water temperatures and evaporation temperatures are the same. However, the mass flow of the refrigerant that produces the same heat flow rate in the condenser or gas cooler is much bigger in the case of $\mathrm{CO}_{2}$ by a factor of 7.2 compared to $\mathrm{NH}_{3}$.

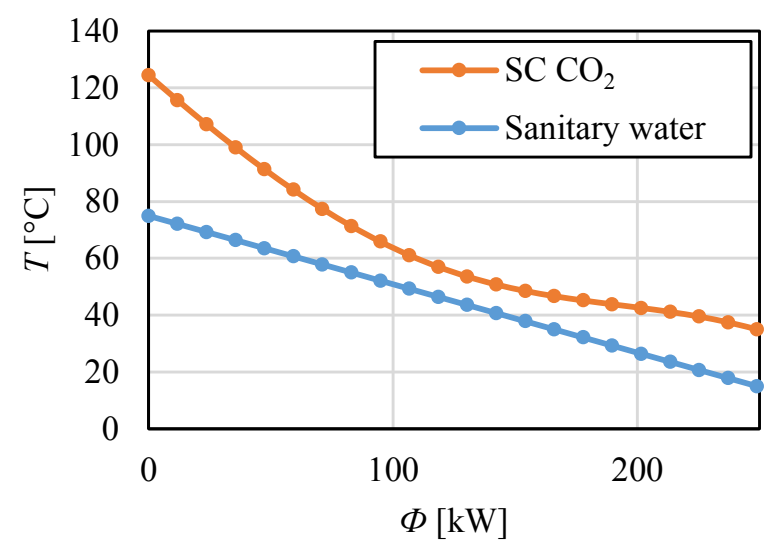

Fig. 5. Temperature curves for the gas cooler of the transcritical $\mathrm{CO}_{2}$ heat-pump at $T_{e}=0{ }^{\circ} \mathrm{C} ; T_{w}=75^{\circ} \mathrm{C}$

Fig. 6 presents the results of calculations of COP values dependent on the outlet temperatures of hot sanitary water for the transcritical heat-pump using $\mathrm{CO}_{2}$ as a refrigerant. The simulations were carried out at different refrigerant evaporation temperatures $\left(T_{e}\right)$, ranging from $-20{ }^{\circ} \mathrm{C}$ to $20^{\circ} \mathrm{C}$. It should be noted that all transcritical heat-pump cases were simulated as a single stage heat-pump, meaning that only one compressor was used in the cycle. On the other hand, the ammonia HTHP was simulated as a single stage heat-pump for the evaporation temperatures above $15^{\circ} \mathrm{C}$ and as a double stage heat-pump for the evaporation temperatures below $10{ }^{\circ} \mathrm{C}$. Fig. 7 presents the results of calculations of COP values dependent on the outlet temperatures of hot sanitary water for the HTHP that uses ammonia as a refrigerant.

When comparing the results of both simulations, it can be seen that the ammonia HTHP is overall better in terms of COP. For example: in the case of the production of hot sanitary water at $75{ }^{\circ} \mathrm{C}$ and at evaporation temperature of $20{ }^{\circ} \mathrm{C}$ (meaning that low temperature heat source would be available at temperatures greater than $25^{\circ} \mathrm{C}$ ) COPs would amount to 5.18 and 4.4 for the ammonia heat-pump and transcritical $\mathrm{CO}_{2}$ heat-pump, respectively.

The differences between the COP values of both heat-pumps, Table 1, were the highest in the case of high evaporation temperature - in the range between 0.73 and 0.88 On the other hand, this difference was the lowest at low evaporation temperatures, ranging 


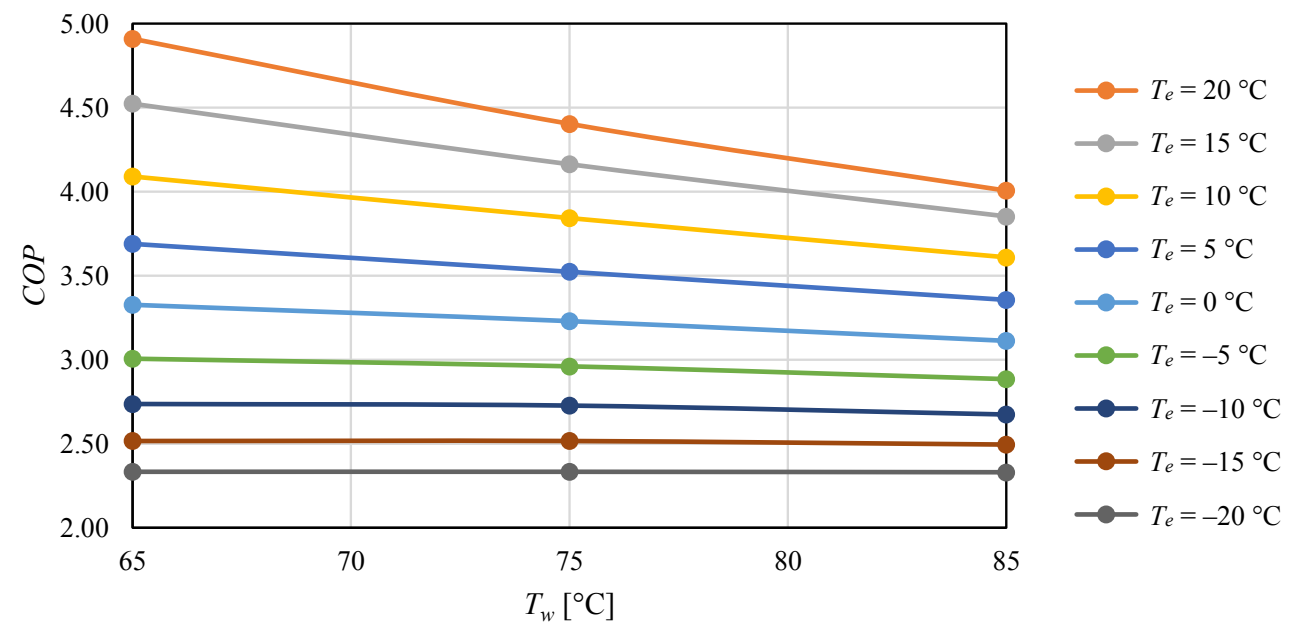

Fig. 6. $\mathrm{COP}$ dependent on the sanitary water temperature for the transcritical heat-pump $\left(\mathrm{CO}_{2}\right)$

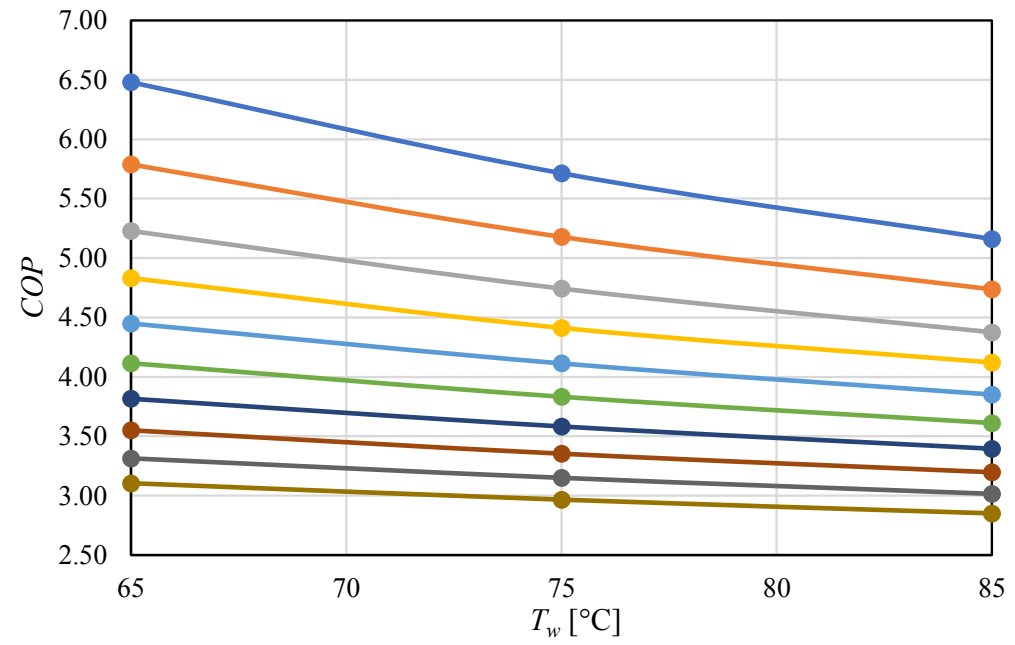

$$
\begin{aligned}
& \multimap T_{e}=25^{\circ} \mathrm{C} \\
& -T_{e}=20^{\circ} \mathrm{C} \\
& -T_{e}=15^{\circ} \mathrm{C} \\
& \multimap T_{e}=10^{\circ} \mathrm{C} \\
& -T_{e}=5{ }^{\circ} \mathrm{C} \\
& \multimap T_{e}=0{ }^{\circ} \mathrm{C} \\
& -T_{e}=-5{ }^{\circ} \mathrm{C} \\
& -T_{e}=-10^{\circ} \mathrm{C} \\
& -T_{e}=-15^{\circ} \mathrm{C} \\
& -T_{e}=-20^{\circ} \mathrm{C}
\end{aligned}
$$

Fig. 7. COP dependent on the sanitary water temperature for the $\mathrm{HTHP}\left(\mathrm{NH}_{3}\right)$

from 0.52 to 0.77 . Outlet water temperatures have a

\begin{tabular}{|c|c|c|c|c|c|c|c|c|c|}
\hline & \multicolumn{9}{|c|}{$T_{e}\left[{ }^{\circ} \mathrm{C}\right]$} \\
\hline & 20 & 15 & 10 & 5 & 0 & -5 & -10 & -15 & -20 \\
\hline$\sigma 65$ & 0.88 & 0.70 & 0.74 & 0.76 & 0.79 & 0.81 & 0.81 & 0.80 & 0.77 \\
\hline 075 & 0.77 & 0.58 & 0.57 & 0.59 & 0.60 & 0.62 & 0.63 & 0.63 & 0.63 \\
\hline 85 & 0.73 & 0.52 & 0.51 & 0.50 & 0.50 & 0.51 & 0.52 & 0.52 & 0.52 \\
\hline
\end{tabular}
similar influence on the difference between the COP values of both heat-pumps. The COP value was the highest in the case of low sanitary water temperatures $\left(65^{\circ} \mathrm{C}\right.$ ) ranging from 0.70 to 0.88 , and the lowest at high sanitary water temperatures $\left(85^{\circ} \mathrm{C}\right)$ ranging from 0.5 to 0.73 .

Table 1. Differences between COP values of both heat-pump technologies dependent on evaporation temperature and hot water temperature

\section{CONCLUSIONS}

Two different heat-pumps were presented and compared during this research work. The simulation models and assumptions were designed in a way to enable a fair comparison between these two technologies. The results of the simulations showed that ammonia outperforms carbon dioxide when used as a refrigerant for the production of hot sanitary water. Two main reasons why the ammonia HTHP outperforms the transcritical $\mathrm{CO}_{2}$ heat-pump could be the following:

- a better isentropic efficiency of ammonia compressor,

- the fact that ammonia can transfer more heat per unit of mass or volume than $\mathrm{CO}_{2}$. 
However, when deciding for the most profitable technology there are more factors to consider than just the COP. The investment costs of both technologies are one of the more important factors. It is expected that the cost for the transcritical $\mathrm{CO}_{2}$ heat-pump would be higher than that of ammonia HTHP, due to higher pressures in the transcritical $\mathrm{CO}_{2}$ heat-pump and an additional internal heat exchanger. On the other hand, double stage HTHP is needed in the case of low evaporation temperatures, which also increases the capital costs. Those heat-pump technologies can be used in the cases where cooling and heating is required at the same time. Food industry (for example meat and dairy industry) is especially suitable, because hot water and refrigeration are needed at the same time.

Further work should include a detailed designing and simulations of gas cooler, condenser, evaporators and internal heat exchanger including pressure drop analyses and optimisation of the operation of both heat-pumps. The comparison should also be extended to district heating applications, by using two stage transcritical heat-pumps if necessary. In this way, low temperature water sources could be exploited for district heating applications.

\section{REFERENCES}

[1] Olabi, A. G. (2016). Energy quadrilemma and the future of renewable energy. Energy, vol. 108, p. 16, D0l:10.1016/j. energy.2016.07.145.

[2] Kulcar, B., Goricanec, D., Krope, J. (2008). Economy of exploiting heat from low-temperature geothermal sources using a heat pump. Energy and Buildings, vol. 40, no. 3, p. 323-329, D0I:10.1016/j.enbuild.2007.02.033.

[3] Goričanec, D., Pozeb, V., Tomšič, L. Trop, P. (2014). Exploitation of the waste-heat from hydro power plants. Energy, vol. 77, p. 220-225, D0I:10.1016/j.energy.2014.06.106.
[4] Caf, A., Urbancl, D., Trop, P., Goricanec, D. (2016). Exploitation of low-temperature energy sources from cogeneration gas engines. Energy, vol. 108, p. 86-92, D0l:10.1016/j. energy.2015.09.119.

[5] Zhao, Z., Xing, Z. Hou, F., Tian, Y., Jiang, S. (2016). Theoretical and experimental investigation of a novel high temperature heat pump system for recovering heat from refrigeration system. Applied Thermal Engineering, vol. 107, p. 758-767,. DOI:10.1016/j.applthermaleng.2016.07.047.

[6] Blarke, M. B. (2012). Towards an intermittency-friendly energy system: Comparing electric boilers and heat pumps in distributed cogeneration. Applied Energy, vol. 91, no. 1, p. 349-365, D0I:10.1016/j.apenergy.2011.09.038.

[7] Bai, T., Yan, G., Yu, J. (2015). Thermodynamic analyses on an ejector enhanced $\mathrm{CO} 2$ transcritical heat pump cycle with vapor-injection. International Journal of Refrigeration, vol. 58, p. 22-34, D0I:10.1016/j.jijrefrig.2015.04.010.

[8] Zha, S., Hafner, A., Nekså, P. (2008). Investigation of R-744 Voorhees transcritical heat pump system. International Journal of Refrigeration, vol. 31, no. 1, p. 16-22, D0l:10.1016/j. ijrefrig.2007.06.017.

[9] Li, X., Li, M., Ma, Y., Yan, Q. (2013). The influence of nitrogen on an expander in a carbon dioxide transcritical heat pump. Applied Thermal Engineering, vol. 59, no. 1-2, p. 182-188, DOI:10.1016/j.applthermaleng.2013.05.037.

[10] Pearson, A. (2008). Refrigeration with ammonia. International Journal of Refrigeration, vol. 31, no. 4, p. 545-551, D0I:10.1016/j.jjrefrig.2007.11.011.

[11] Sarkar, J., Bhattacharyya, S., Ram Gopal, M. (2007). Natural refrigerant-based subcritical and transcritical cycles for high temperature heating. International Journal of Refrigeration, vol. 30, no. 1, p. 3-10, D0l:10.1016/j.jijrefrig.2006.03.008.

[12] Mayekawa Mycom, $\mathrm{CO}_{2}$ Supercritical Heat pump from http:// www.mayekawa.com, accessed on 2015-04-20.

[13] Fouad, W.A., Vega, L. F. (2018). Transport properties of HFC and HFO based refrigerants using an excess entropy scaling approach. The Journal of Supercritical Fluids, vol. 131, pp. 106-116, D0l:10.1016/j.supflu.2017.09.006.

[14] Aspen Technology, Inc, Aspen Plus V8.6. 2015. 